\title{
A little knowledge being a dangerous thing?: Decile-based approaches to developing NCEA league tables
}

\section{MARTin Thrupp \& NoEline AlCoRN}

\begin{abstract}
In recent years it has become increasingly common for New Zealand newspapers and magazines to publish "league tables" comparing schools' performances in National Certificate of Educational Achievement (NCEA). Since these results strongly reflect socioeconomic differences between schools, some media outlets have taken up the practice of arranging school results by socio-economic deciles and/or providing decile "averages". Although this approach is intended to indicate more clearly "value added" than approaches that do not group schools by decile, this article urges caution towards decile-based comparisons on the grounds that schools have numerous contextual differences that are not reflected in decile ratings. The problem is illustrated here by comparing findings from research in two schools with the same decile rating. We conclude that taking account of deciles does not make judgments about school NCEA performance more defensible, and suggest that the practice be discouraged.
\end{abstract}

Jew Zealanders have long taken an interest in schools' results in 1 external qualifications, with the middle classes, in particular, using them as one source of information for choosing schools and maintaining "positional advantage" within the education system (Lauder et al., 1999; McKenzie, Lee, \& Lee, 1996). Responding to this demand, in recent years it has become increasingly common for New Zealand newspapers to publish "league tables" of the National Certificate of Educational Achievement (NCEA) results gained in schools locally, regionally or New Zealand-wide. As these NCEA 
results strongly reflect socio-economic differences between schools, some media outlets have also taken up the practice of arranging schools by socio-economic deciles and/or comparing against decile "averages". In commentary around the league tables, the decile-based approach to analysing NCEA data is claimed to be fairer and more helpful than other approaches because it indicates more effectively the "value added" by schools.

Nevertheless decile-based comparisons are very much a case of using available data rather than good data. This articles urges caution on the grounds that schools have numerous contextual differences not signalled by decile ratings. The problem of using deciles as the basis for comparing school performance is mainly illustrated here by comparing findings from research in two schools with the same decile rating. We begin our discussion by noting a range of research literature relevant to the relationship between school context and school performance. We then turn to the decile indicator and the way it is being used in NCEA league tables. The final section of the article provides an example of school differences within deciles using the cases of two decile 8 schools we have called "Gandalf College" and “Tolkien High School.”

\section{School context and school performance}

There are several literatures that provide support for the idea that school contexts, in all their richness, have to be taken into account when assessing the performance of schools based on student achievement. To begin with, numerous studies within the sociology of education over the last fifty years have measured and sought to explain the considerable extent to which "home backgrounds" of students, usually seen mainly in terms of social class or socioeconomic status, influences student achievement. New Zealand perspectives on the extensive international literature have been provided by Biddulph, Biddulph and Biddulph (2003) and more recently, by Snook and O’Neill (2010). Relevant New Zealand studies include those that stem from the quantitative "political arithmetic" tradition (e.g., Fergusson, Horwood, \& Boden, 2008; Lauder \& Hughes, 1990; Nash \& Harker, 1998; Wylie, Hodgen, Hipkins, \& 
Vaughan, 2006) and more qualitative case studies and theoretical accounts (e.g., Jones, 1991; Nash, 1993). The OECD's analysis of 2009 PISA data, which includes data from NZ schools, further stresses the impact of socio-economic backgrounds on student achievement:

Home background influences educational success, and schooling often appears to reinforce its effects. Although poor performance in school does not automatically follow from a disadvantaged socioeconomic background, the socio-economic background of students and schools does appear to have a powerful influence on performance. (OECD, 2010, p. 13)

There are also research studies concerned with how the overall characteristics of school intakes or other dimensions of school context impact on school performance. In this area the New Zealand quantitative literature has been more contested with Lauder and colleagues (Lauder et al., 1999) arguing for strong "school mix" or contextual effects on student achievement while Nash and Harker (1998) found that contextual effects were negligible. The same kind of debate can be seen in the international literature as well (see Thrupp, Lauder, \& Robinson, 2002 for discussion and explanations). PISA analysis again provides support for the view that socio-economic contexts do make a difference:

Regardless of their own socio-economic background, students attending schools with a socio-economically advantaged intake tend to perform better than those attending schools with more disadvantaged peers. (OECD, 2010, p.13)

Qualitative accounts from New Zealand and overseas help to explain why school context is important (Braun, Ball, Maguire, \& Hoskins, 2011; Carrasco-Rozas, 2010; Lupton, 2004; Mills \& Gale, 2009; Thrupp, 1999; Thrupp \& Lupton, 2011). Most of these studies stress that socio-economically similar schools have many other contextual differences. These include other intake differences (such as ethnicity, turbulence, the proportion of pupils from refugee families or with special needs) and other school and area characteristics (urban/rural location, local education policies, market position compared to surrounding schools). Braun and colleagues, writing in the English context, suggest four types of school context: 
- Situated contexts (such as locale, school histories, intakes and settings).

- Professional contexts (such as values, teacher commitments and experiences and 'policy management' in schools).

- Material contexts (e.g. staffing, budget, buildings, technology and infrastructure).

- External contexts (e.g. degree and quality of local authority support, pressures and expectations from broader policy context, such as Ofsted ratings, league table positions, legal requirements and responsibilities). (Braun et al., p. 588)

Other literatures which are relevant include those on the challenges of school effectiveness and improvement in low socio-economic settings (Harris, James, Gunraj, James, \& Clarke, 2006: Mortimore, 1997) and those on the problem of governments preferring to position teachers and schools as being primarily accountable for student achievement despite the research already mentioned (Nash \& Prochnow, 2004; Thrupp, 2009).

\section{Deciles and their use in NCEA league tables}

New Zealand's school decile indicator shows the extent to which schools have a low socio-economic (SES) intake, with decile 1 having the highest proportion of low SES students and decile 10 having the smallest proportion. ${ }^{1}$ The decile rating was originally developed as a means of targeting funding to schools, and while it has subsequently become a more widely used indicator of school SES, it is important to recognise that some features of the decile system have always made it unsuitable for use in "high-stakes" comparative ways. First, the indicator is based on a range of socio-economic information drawn from the census and because this information is not available at the level of individual households (for privacy and other reasons), school ratings can only be developed by attributing to a school the characteristics of all households with school-age children in the census "meshblock" areas where that school's students live. The difficulty with this method is that the characteristics attributed will not be very accurate in some situations, even if the general methodology 
is sound. ${ }^{2}$ Second, the decile system focuses on the proportion of low SES students; it is not an indicator of overall school mix or intake profile. This means that while school intakes around the extremes of deciles 1, 2, 3 and 8, 9,10 might usually be assumed to have many or few low SES students respectively, for schools with ratings between these extremes, the picture is much less clear. In such schools the same rating might represent SES profiles that are highly polarised or more uniform.

Despite these problems, the decile indicator has now become contextual information often provided with NCEA "league tables". These usually appear in the media in April after the data for the previous year's NCEA results become available on the New Zealand Qualifications Authority (NZQA) website in late March. Figure 1 below shows a section of the table provided to readers of the Sunday Star Times in 2010. There are more data that newspapers could source from the NZQA website but data presented here illustrate what is typically in the NCEA league tables. There is the decile, the size of the school roll, pass rates for NCEA levels for the consecutive years during which most students are assessed for those levels, and pass rates for the combination of credits that are required for entrance to university. 


\begin{tabular}{lcccccc}
\hline School & Recile & Roll & $\begin{array}{c}\text { Level 1 at } \\
\text { Year 11 }\end{array}$ & $\begin{array}{c}\text { Level 2 at } \\
\text { Year 12 }\end{array}$ & $\begin{array}{c}\text { Level 3 at } \\
\text { Year 13 }\end{array}$ & UE \\
Akaroa Area School & 8 & 132 & 100 & 100 & 50 & 62.5 \\
Al-Madinah School & 2 & 457 & 87.5 & 90.9 & 100 & 46.7 \\
Albany Senior High School & 10 & 229 & 78.8 & & & \\
Alfriston College & 3 & 1219 & 64.1 & 54.5 & 50.5 & 41.8 \\
Amuri Area School & 8 & 284 & 56.3 & 76.9 & 37.5 & 37.5 \\
Aorere College & 2 & 1461 & 53.8 & 61.5 & 47.1 & 42.9 \\
Aotea College & 5 & 957 & 69.8 & 64.1 & 49.4 & 37 \\
Aparima College & 5 & 205 & 77.1 & 43.8 & 83.3 & 33.3 \\
Aquinas College & 9 & 772 & 89.2 & 95 & 93.8 & 88.9 \\
Aranui High School & 2 & 634 & 59.4 & 42.2 & 25 & 21.9 \\
Araura College & & & 37.2 & 85.7 & & \\
Ashburton College & 7 & 1158 & 63.6 & 70.4 & 59.7 & 62.1 \\
Auckland Girls' Grammar & 5 & 1371 & 72.1 & 79.4 & 73.1 & 72.5 \\
Auckland Grammar School* & 10 & 2432 & 70.3 & 82 & 58 & 61.5
\end{tabular}

Figure 1, Section of NCEA results tables from Sunday Star Times, 11 April 2010

Media discussion that accompanies such NCEA data shares some of the characteristics of coverage of school achievement league tables in other countries such as England. For instance, there is often discussion about whether overall success rates have improved or declined from previous years, and many local newspapers note which schools have been top performers locally. Nevertheless, the coverage of NCEA results has little of the intensity found elsewhere. To some extent this may be because New Zealanders are less concerned about education than those in more competitive societies such as England (see Thrupp, 2001 for a discussion). However, it is also likely that the sheer complexity of NCEA helps to dissipate some of the effects of interschool comparison. It can be seen from the example provided that even the headline statistics for NCEA are quite complicated because there are several of them and because they are muddied by student pathways where students may pass NCEA levels in "atypical” years (for instance, students who achieve level 1 or level 3 in Year 12). 
Indeed what has become a central feature of the discussion around NCEA league tables each year is the fairness of comparing school results. As Little (2011) puts it, "NCEA-bashing season starts earlier every year...usually the complaints involve accusations of graderigging and jiggery-pokery behind the scenes to make schools appear to be doing a better job than they really are". Usually it is the behaviour of schools that is in the spotlight. One issue which has been repeatedly raised is the problem that some schools offer more "easy" unit standards than others, allowing them to look more successful when they achieve higher pass rates than schools doing more difficult "achievement standards" (Beaumont, 2009). Another concern often raised is the problem of "credit cleansing", schools boosting their pass rates by cancelling the NCEA enrolments of students who are unlikely to be successful (Grunwell, 2011). A further problem rarely noted is that school intakes will vary from year to year in terms of prior ability and therefore their propensity to do well in NCEA. When results are provided for the current year only, they may not be typical of patterns over time.

Nevertheless, it is the idea that high and low SES schools should not be expected to achieve the same levels of success because their students are dealing with different levels of social advantage/ disadvantage that is perhaps the most widely understood issue about comparing the NCEA tables. Comparing overall results by decile is certainly instructive about the relationship between socio-economic differences in school intakes and student achievement in New Zealand. For instance, Figure 2 is taken from the same NCEA 2009 data as illustrated by Figure 1 but shows the means across all New Zealand schools by decile for those achieving level 1 at Year 11 and those achieving University Entrance. ${ }^{3}$ It can be seen that student success in achieving level 1 at Year 11 increases fairly steadily as school intakes become more socially advantaged, and this pattern is clearer still for University Entrance. 


$\begin{array}{ccc}\text { Decile } & \text { \% achieving NCEA level 1 at Year 11 } & \text { \% UE } \\ 1 & 61.7 & 43.3 \\ 2 & 64.8 & 42.5 \\ 3 & 69.1 & 51.6 \\ 4 & 66.6 & 56.0 \\ 5 & 72.2 & 55.9 \\ 6 & 73.7 & 59.8 \\ 7 & 78.3 & 66.7 \\ 8 & 78.0 & 67.3 \\ 9 & 85.0 & 73.7 \\ 10 & 88.6 & 85.1\end{array}$

Figure 2. Mean 2009 NCEA results across all New Zealand secondary schools by decile for those achieving level 1 at Year 11 and those achieving University Entrance

Recognising that school achievement varies by decile, the New Zealand Herald, New Zealand's largest circulating newspaper, has over the last two years (2010 and 2011) published its NCEA results by decile. The form of these is illustrated by Figure 3 which shows the decile 9 section of the 2010 results table published in the Herald in April 2011. Commentary in this newspaper is also becoming structured by decile. For instance an article on Mangere College subtitled "Must do better" (Binning, 2011) was accompanied by a small table showing Mangere College's achievement compared to the average of all decile 1 schools. ${ }^{4}$ In taking this approach, the Herald may have followed the lead of Auckland's Metro magazine which, over the last three years, has made a feature of its "unique" addedvalue approach to assessing schools against "decile averages" for all Auckland schools (Wilson, 2009, 2010; Wilson, with McGregor, 2011):

We took the schools' pass rates as published by the New Zealand Qualifications Authority and calculated the average for each decile. We then calculated how well each school did in relation to that "decile average". This provides our measure of "added value": what the school has contributed to raise or lower its students' achievements. (Wilson, 2009, p. 32) 


\section{DECILE 9}

Aqunas College, Tauranga

Earadene Cpllege, Remuera

Cambrige Hgh School cambridge

Elm Christian College, Botany

Epoom Girts Grammar, Epeom

Glendowe College, Glendowe

Hamiton Crristlan School

Havelock North High School,

Havelock Horth

bna College, Havalock North

Mchael Park School, Ellerslle

Newhands College, Wellngton

"Nga Tawa Dbcesan school, Marton

Northcote College, Northcute

Orewa College, Orewa

"Palmerston North Boys' High

School, Palmerston North

Palmerston North Girs' Hgh Sctool,

Falmerston Horth

Fathkeale College, Masterton

Fosmini College, Takapuna

Salnt Mary's College, Wellngton

"Salnt Patricks College, Simerstream

St Matthew's Colleg ate, Masterton

Tawa College, Wellington

Wellngton HIgh Schcol, Wellington

'Westake Boys' High School,

Takapuna.

"Westake Gris' High school,

Takapuna

Whangaparaoa college.

Whangaparaoa

woodford House, Havelock North

ALL DECILE 9 SGHOOLS

\begin{tabular}{|c|c|c|c|c|c|c|c|}
\hline 92 & +3 & 86 & -9 & 88 & -6 & 75 & -14 \\
\hline 97 & +9 & 98 & -1 & 93 & +11 & 87 & +4 \\
\hline 80 & -8 & 94 & +5 & 81 & +3 & 67 & +10 \\
\hline 74 & -4 & 89 & +10 & 77 & +1 & 75 & -1 \\
\hline 86 & -3 & 89 & $\mathrm{MC}$ & 85 & $\mathrm{Mc}$ & 84 & +2 \\
\hline 82 & +3 & 92 & +7 & 84 & +3 & 85 & +8 \\
\hline 67 & -25 & 90 & -7 & 88 & +29 & 88 & +13 \\
\hline 78 & +11 & 80 & +9 & 73 & +8 & 76 & +7 \\
\hline 98 & +3 & 100 & +3 & 97 & +2 & 88 & +1 \\
\hline & $\mathrm{N} / \mathrm{A}$ & 82 & -7 & 76 & +14 & 71 & +16 \\
\hline 75 & -8 & 85 & +6 & 73 & +7 & 70 & +5 \\
\hline 100 & $\mathrm{~N} \mathbf{C}$ & 100 & $\mathrm{NCC}$ & 98 & +1 & 90 & +8 \\
\hline 67 & +3 & 82 & +7 & 73 & +1 & 69 & +2 \\
\hline 84 & +3 & 90 & +5 & 86 & +14 & 75 & +5 \\
\hline 74 & -8 & 83 & +5 & 76 & -8 & 72 & -6 \\
\hline 86 & $\mathrm{~N} / \mathrm{C}$ & 86 & -3 & 83 & -1 & 81 & +1 \\
\hline 74 & -20 & 94 & -4 & 82 & -8 & 78 & -8 \\
\hline 95 & +2 & 92 & +3 & 80 & -2 & 78 & No \\
\hline 94 & +2 & 87 & -2 & 82 & +2 & 72 & -1 \\
\hline 86 & -1 & 91 & +1 & 81 & +20 & & +17 \\
\hline 100 & +3 & & $N / A$ & & WA & & WA \\
\hline a3 & +3 & 80 & -4 & 77 & +4 & 67 & -1 \\
\hline 70 & -4 & 79 & +9 & 74 & +9 & 69 & +8 \\
\hline 81 & +13 & 77 & +5 & 68 & -4 & 70 & +1 \\
\hline 86 & $\mathrm{NoC}$ & 92 & +1 & 86 & +3 & 84 & +2 \\
\hline 85 & +10 & 73 & +5 & 64 & +16 & 64 & +10 \\
\hline 91 & -3 & 98 & -2 & 96 & -2 & 96 & -2 \\
\hline 63 & & 67 & +2 & 79 & +3 & 74 & +1 \\
\hline
\end{tabular}

THE RESULTS ARE FOR:

Leval 1 - Vear 11

Level 2 - Year 12

Level 3 - Year 13

University Entrance - Year 13

(Figure on the left is 2010 percentage, right nest to it is how many percentage points it's increased/decreased since 2009)
W/A - result not available
N/C - no change since 2009
- School also offers Cambridge Exams
* School also offers International Baccalaureate

Figure 3. Section of 2010 NCEA results table (New Zealand Herald, p. A11, April 18, 2011) 
The "by decile" approach taken by the Herald and the decile averagebased measures used by Metro both recognise that it is problematic to compare schools across deciles but seem to assume that it is fair to compare schools within decile. Yet as noted earlier, SES characteristics are likely to vary within deciles, especially for schools towards the middle of the range, and researchers are also pointing to the significance of many other kinds of context. This article now turns to a recent study of secondary schools and in particular compares and contrasts two decile 8 secondary schools within the study. The point of this exercise is to illustrate that while basing "value added" on decile might be convenient in terms of the ready availability of the decile indicator, it is often likely to be inadequate as a means of taking account of school context.

\section{“Gandalf College” and "Tolkien High School”}

There is a considerable body of research that seeks to understand the way teaching and learning are affected by various elements of school context (Lupton, 2004; Metz, 1990; Mills \& Gale, 2009; Smyth \& McInerney, 2007; Thrupp, 1999; Thrupp \& Lupton, 2011; Thomson, 2002). Relevant aspects of school context include student intake characteristics, school history and location, and relationships with other local schools. Our research, the "Secondary contexts and staff beliefs project," was designed to investigate how and to what extent contextual features impact on the beliefs New Zealand teachers and principals hold about teaching and learning, the extent to which they believe their agency can effect changed outcomes for their students, and the aspirations and goals they pursue. To investigate these issues we undertook research in six secondary schools. We visited each school twice to interview principals and up to five teachers, collecting data on the context of the school and on staff beliefs, assumptions and goals. As well as local contextual issues we were interested in the impact of the broader national context of increasing accountabilities, the new New Zealand curriculum document, developments in ICT, and international surveys of literacy, mathematics and science. 
Our choice of schools was somewhat opportunistic but reflected our understanding that the SES make-up of school intakes has a considerable influence on school processes and culture. Thus our sample included schools ranging from decile 1 to decile 8 . As might be expected from other studies, our data revealed significant differences between deciles - particularly the impact of the socioeconomic differences between the decile 8 and decile 1 schools (Alcorn \& Thrupp, 2011). However, there were also significant within-decile differences between the two suburban decile 8 schools, based primarily on the different character of the middle-class neighbourhoods they served, and it is these we are concerned with here.

"Gandalf College" and "Tolkien High School" were both large, popular schools and, like other high decile schools around New Zealand, they had considerable success in academic, sporting and cultural activities. They had few problems recruiting staff except sometimes in particular subject areas. A high proportion of their students remained at school for five years and continued into tertiary education. The schools were well supported by their parent communities, enrolled international fee-paying students and held ballots for out-of-zone students. Both schools had a predominance of Pākehā/European students but whereas Tolkien had a range of ethnic groups, with a growing number of Asian students, Gandalf's student body was more clearly either Pākehā or Māori. These and other contextual differences led to significant differences in emphasis around teaching and learning, even while the schools shared much in common.

One difference had to do with the kinds of middle class families each school predominantly served. Gandalf largely served an intake of children of small business owners, relatively well off but often more entrepreneurial than academic in both background and outlook:

You've got to remember that [this area is about] small business. You are not actually breeding hundreds of scholars. It's a lot of successful entrepreneurs' kids that we've got. [The decile's] not an indicator of academia. It might be an indicator of ability because entrepreneurship requires ability but that is not an indicator of academia. And I talked to [a student] the other day who was going on 
to become a successful barista: “I'm not having university crap, I don't need it". Well, that's fine if he wants to end up a successful barista, I think he'll probably be frustrated a bit later on because he is quite able but he might come to it later on... ${ }^{5}$

One effect of Gandalf's intake seemed to be that "vocational” options were valued more than they would have been in some high decile schools, including Tolkien High School. Although both schools offered similar proportions of unit standards and achievement standards in their senior curriculums (approx. 25\% unit standards at Gandalf and 20\% at Tolkien), the understanding that many students, including many able students, did not want to follow an academic programme was stronger at Gandalf:

They're not going to be academic; they need a transitional pathway. Now, you might come back at me, and say "you're imposing your particular set of values on what you think is appropriate for them" but I don't like walking around classrooms here and seeing disengaged children. And, quite frankly, some boys and some girls, more likely male than female, become disengaged in year twelve and if they're going to become engaged by being in an auto workshop, if they're going to become engaged by working in horticulture, then that seems to me to be much better than losing them.

With credential inflation the goalposts have changed even for "non academic” students at Gandalf:

I think that there are a lot of kids who would be very happy to have the successful businesses that their parents have but I don't think they've always thought about what went before getting there, the steps you have to go through to get there. But I think they have...I think they have aspirations to do the same sort of thing, they don't always understand that now to do an apprenticeship you actually need to have year twelve literacy.

In contrast, Tolkien High School had long served a largely welleducated professional intake with particular expectations, even though the proportion of students from lower socioeconomic backgrounds was increasing. It prided itself on being an academic school:

We've always been a school that's wanted to maintain that academic rigour, I suppose. We haven't believed in the fact of doing a whole lot of "easy" unit standards so kids will pass. Yeah ok, we're 
conscious of our pass rates and we want to continue to raise them but it's about the quality of the product, from our perspective, and that's probably why we do so well in Merits and Excellences and Scholarship and kids going to university.

Similarly, although both schools were proud of the extra activities they offered, these were rationalised in a more academic way at Tolkien than at Gandalf:

I mean, they're all achievements as such, we regard them as being co-curricular, so in a sense if you're looking for a Rhodes scholar or you're looking for someone to go to another university; it's actually not just about marks.

At the same time, these outlooks involved different emphases more than anything else. Just as Gandalf was still very proud of its academic successes, Tolkien was concerned with offering some alternative pathways:

But as long as you are tailoring the programme to meet the student needs; and that's why there is still a need to have some unit standards and they're mainly in your sort of maths and numeracy and literacy area.

But it's about designing programmes of learning that meet student needs. [In one area] there are three types of courses you can do: the achievement standards one, the mixture of achievement and unit standards one, and a pure unit standards course. That's perfect. Those students that struggle, they do the unit standards one.

Continuing tensions are likely at Tolkien between catering for an increasingly diverse intake and maintaining an academic emphasis. They can be seen for instance in the way staff at Tolkien were ostensibly committed to a mixed ability approach at the junior level, while some staff mentioned "behind the scenes" screening approaches to support the school's academic emphasis:

We have a review of this on a regular basis and I have to say that the staff are committed not to stream particularly at the junior level...we've got a very definite philosophy in this school about enrichment and extension rather than acceleration. 
I see our year nine semesters as very much a screening process where it's very much a case of sorting out who can and who can't [do our subject], and I know that some of my advisors and other people in the system would have heart attacks to hear me saying that but the reality is that a lot of people leave teaching and become advisors and within sometimes days it seems they forget the reality of being in a classroom.

There were also significant ethnic differences between the schools. Both schools were predominantly Pākehā, but whereas Gandalf had a slightly greater proportion of Māori students, Tolkien had more students from Asia, the Middle East, Latin America and Africa. One effect this had was to make race relations at Gandalf more clearly a matter of Māori/Pākehā sensitivity:

We discussed [Te Kotahitanga] but chose not to go ahead with the project because we had so many other initiatives happening in the school. However, we use 'Culture plus' for staff professional learning because Māori are saying, "well, we learn differently”. In a way I don't doubt that but I don't think in a single nation you want to emphasise that; you want to do it in a way that you can build learning for both groups. ...yes we are $14-15 \%$ Māori and that was another thing we had to watch; and if I had actually put it to the staff and we had over half the staff react negatively, which was a concern, where would we have gone with it?

\section{At Tolkien, there was necessarily a more multicultural focus:}

When I was here in the early eighties, the demographics were quite different....it was essentially Māori and European; Europeandominated with some Māori. But over time that has changed so as a school you've got to change and adapt to that. You can't just think we've always done it this way so we'll always continue to do it that way.

I mean, that's a national trend, the under-achievement of Māori and Pasifika so we get whacked. ERO are less than complimentary about what we do but the reality is that for us, Māori are really just part of the student population and we work with them. I mean, there's a group and all those things that you have but they're just another part, another dimension in our community and we're never going to get 
ourselves attached to big projects like Te Kotahitanga 'cause our Māori population are very low but we can embrace some of the principles involved in it.

An example of a specific way Tolkien was responding to its multicultural intake involved catering for the academic profile of students for whom English was a second language:

Our top students have been students... who have been able to cope with maths, science and English, so their time has been slightly restricted, they've had less time to complete so that the other subject can fit in. However, what we're finding now is that because we have a number of students who might not be as strong in one of those subject areas - so they might be very good at English but they might not be so good at maths and science... So next year we're looking at an structure where the students have the opportunities to take six subjects regardless. They won't have to be science, maths and English.

A further difference between these decile 8 schools involved their coherence as organisational and social institutions. Gandalf was very anchored in its suburb, indeed in many ways it formed the centre of the community:

I went to the First XV game, I was stunned by the number of ex-year 13 kids of the last two years...the entire rugby field was ringed. You see, it is the only institution in white, middle-class suburbia. It is the only institution that brings a sense of community to the area and, in fact, it is the only institution that most people in the community have anything to do with as a single institution. It's probably the one thing in common that most households in the area have actually had anything to do with and we're about to celebrate two staff members who have been there for forty years. Now, in fact, they have huge identity. The long-serving staff provide the community with a great sense of identity.

There was much effort at Gandalf to create a culture that incorporated all staff. For instance, a senior staff member explained "The next meeting is actually on the review of the Gandalf College Lesson Plan and the Gandalf College Unit Planner”. The faculty structure at Gandalf was more pervasive than at Tolkien, possibly reflecting the physical layout as much as anything else: 
The school is very faculty based. It's very faculty based both in its physical layout and in its operations. Every faculty has a centralised resource room. Each faculty has a centralised resource room and that is where the staff meet. They do work; the school runs, basically, on faculty teams.

Tolkien did not seem to play the same role as a focal point for the community, perhaps because there were other important institutions nearby and more choices of other ways to be in the city in which it is located, and with more ethnic diversity it probably did not reflect such a cohesive community in any case.

There were also various indications that the treatment of students as learners was more idiosyncratic and individualised at Tolkien than at Gandalf. Tolkien teachers sought to allow students the opportunity to determine their preferred ways of working. This was part of their push to help students take responsibility for their own learning.

Like, we have rules and they are enforced and ... but I think what makes the difference is the kids are treated as individuals to a large extent...I think in senior management there's a very strong ethic of working with the students as individuals.

There's a strong focus on differentiation. I think teachers are genuinely giving kids choices about how and why and what they do in terms of the outcomes for their work. I always give them a choice of outcomes but the structures are around deadlines and feed-back and feed-forward.

Gandalf College, on the other hand, was more focussed on addressing the needs of groups of students although the culture of this school was also seen as conducive to acceptance of different talents:

Being quirky or slightly out of the ordinary, while it can still be difficult in the junior school, becomes more and more accepted as kids move up. I always feel a sense of pride at the way kids who wouldn't always be accepted in other social situations are embraced.

Although many further contextual differences between Gandalf College and Tolkien High School could be highlighted here, the features discussed already serve to illustrate that in many respects they were quite different schools. Schools can serve different fractions of 
social classes in a way that means that although they have intakes within the same socio-economic bracket, they are actually teaching students from different kinds of class-located families with different aspirations and levels and types of achievement. It may come as no surprise then that one school (Tolkien) was getting success rates up to $10 \%$ higher than the other (Gandalf). While we are not able to demonstrate that this NCEA achievement difference is caused by the differences we have highlighted, we have illustrated that the schools were working within different sets of parameters in a way that would make it surprising if they did both come close to some kind of decile average.

\section{Conclusion}

The cases of Gandalf College and Tolkien High School illustrate how unrealistic it may be to expect schools in the same decile to have the same levels of achievement. Clearly schools in the same decile can still vary considerably in the kinds of students they have and the expectations and aspirations those students arrive at school with. Using decile averages as some kind of crude value-added indicator that schools can be measured against is also problematic because so many other contextual differences may impact on NCEA results as well.

It might be argued that decile-based approaches to comparing schools are preferable to alternatives that make no attempt to look at value added. However, in our view decile-based approaches are more a case of "a little knowledge being a dangerous thing". This is because when people understand that results are likely to reflect socioeconomic differences, they are also likely to be cautious around claims of school performance. But once it is believed that judgments are sound because value-added has been taken into account (even if it actually hasn't), teachers and schools find themselves without recourse to contextual arguments, for instance any claim that "our results reflect our intake”. It is also important to recall the other kinds of concerns around the NCEA league tables noted earlier: the type of credits and different proportions of students enrolled in NCEA across 
different schools and "natural" variations in intakes from year to year. Taking account of deciles does nothing to address these problems either.

One way forward would be for practitioners and the NZQA to reject and discourage decile-based approaches to comparing NCEA results. Principals and teachers can do this by avoiding such comparisons in their public communications, however tempting they may be in some schools. A useful internal alternative may be to compare student NCEA achievements to their entry-level data. This is also not without problems, but may allow schools to consider their effectiveness with intakes without running into all the difficulties of inter-school comparison.

For the NZQA, the issue is whether it is doing enough to prevent decile-based comparisons. Certainly it advises users of its data that:

Schools vary greatly in their demographic characteristics. Demographic characteristics influence performance in assessments. A comparison of schools is therefore meaningless without taking careful account of demographic differences between them. (NZQA, 2010, p. 35)

On the other hand, decile-based comparisons are encouraged by the NZQA website which allows NCEA data to be displayed by decile. We think the website should be changed to avoid this. While it might be argued that other agencies such as ERO and the Ministry of Education also employ the decile indicator, it is the way NCEA data can be sorted by decile to allow the illusion of fair school comparisons that makes it particularly important that NZQA does all it can to indicate that such comparisons are not defensible. 


\section{References}

Alcorn, N., \& Thrupp, M. (2011). Uncovering meanings: The discourses of teaching in context. Unpublished paper.

Beaumont, N. (2009). NCEA standards 'misleading.' Dominion Post, 25 May.

Biddulph, F., Biddulph, J., \& Biddulph, C. (2003). The complexity of community and family influences on children's achievement in New Zealand: Best evidence synthesis iteration. Wellington: Ministry of Education.

Binning, E. (2011). Must do better: Mangere College principal says lowly statistics fail to explain full story. New Zealand Herald, April 18, A11.

Braun, A., Ball, S.J., Maguire, M., \& Hoskins, K. (2011). Taking context seriously: Towards explaining policy enactments in the secondary school, Discourse: Studies in the Cultural Politics of Education, 32(4), 585-596.

Carrasco-Rozas, A. (2010). A case-study of the Chilean policy agenda for disadvantaged primary schools: Meeting their challenges. Unpublished $\mathrm{PhD}$ thesis, University of Cambridge.

Fergusson, D., Horwood, L., \& Boden J. (2008). The transmission of social inequality: Examination of the linkages between family socioeconomic status in childhood and educational achievement in young adulthood. Research in Social Stratification and Mobility, 26, 277-295.

Grunwell, R. (2011). Credits crisis for NCEA pupils. New Zealand Herald, May 8.

Harris, A., James, B., Gunraj, J., James, S., \& Clarke P. (2006). Improving schools in Exceptionally challenging circumstances: Tales from the frontline. London: Continuum.

Jones, A. (1991). At school I've got a chance. Palmerston North: Dunmore Press.

Lauder, H., \& Hughes, D. (1990). Social origins, destinations and educational inequality. In J. Codd, R. Harker \& R. Nash (Eds.), Political issues in New Zealand education (pp. 43-61). Palmerston North: Dunmore Press.

Lauder, H., Hughes, D., Watson S., Waslander, S., Thrupp, M., Strathdee, R. et al. (1999). Trading in futures: Why markets in education don't work. Buckingham: Open University Press.

Little, P. (2011). School system success. Herald on Sunday, July 31.

Lupton, R. (2004). Schools in disadvantaged areas: Recognising context and raising performance (CASE paper 76). London: Centre for Analysis of Social Exclusion, London School of Economics and Political Science. 
McKenzie, D., Lee, H., \& Lee, G. (1996). Scholars or dollars? Selected historical case studies of opportunity costs in New Zealand education. Palmerston North: Dunmore Press.

Metz, M. H. (1990). How social class differences shape teachers' work. In M. W. McLaughlin, J. E. Talbert, \& N. Bascia (Eds.),The contexts of teaching in secondary schools (pp. 40-107). New York: Teachers College Press.

Mills, C., \& T. Gale. (2009). Schooling in disadvantaged communities: Playing the game from the back of the field. New York: Springer.

Mortimore, P. (1997). Can effective schools compensate for society? In A. H. Halsey, H. Lauder, P. Brown, \& A. Stuart Wells (Eds.), Education, culture, economy and society (pp.476-487). Oxford: Oxford University Press.

Nash, R., \& Harker R. (1998). Making progress: Adding value in secondary education. Palmerston North: ERDC Press.

Nash, R., \& Prochnow, J. E. (2004). Is it really the teachers? An analysis of the discourse of teacher effects on New Zealand education policy. New Zealand Journal of Educational Studies, 39(2), 175-193.

Nash, R. (1993) Succeeding generations. Auckland: Oxford University Press.

NZQA. (2010) Secondary school data and statistics on the NZQA website. Wellington: Author.

OECD. (2010), PISA 2009 results: Overcoming social background - Equity in learning opportunities and outcomes (Volume II). Retrieved from http://dx.doi.org/10.1787/9789264091504-en

Smyth, J., \& McInerney, P. (2007). Teachers in the middle: Reclaiming the wasteland of the adolescent years of schooling. New York: Peter Lang.

Snook, I., \& O’Neill, J. (2010). Social class and educational achievement: Beyond ideology. New Zealand Journal of Educational Studies, 45(2), 3-18.

Thomson, P. (2002). Schooling the rust-belt kids: Making the difference in changing times. Stoke-on-Trent: Trentham Books.

Thrupp, M., \& Lupton, R. (2011). Variations on a middle class theme: English primary schools in socially advantaged contexts. Journal of Education Policy, 26(2), 289-312.

Thrupp, M. (1999). Schools making a difference: Let's be realistic! School mix, school effectiveness and the social limits of reform. Buckingham: Open University Press. 
Thrupp, M. (2001). Education policy and social class in New Zealand and England: An instructive comparison. Journal of Education Policy, 16(4), 297-314.

Thrupp, M. (2009). Teachers, social contexts and the politics of blame. Queensland Teacher's Union Professional Magazine, November, 6-12.

Thrupp, M., Lauder, H., \& Robinson, T. (2002). School composition and peer effects. International Journal of Educational Research, 37(5), 483-504.

Wilson, S. (2009). The best schools in Auckland. Metro, 335, July-August, 30-37 \& 123.

Wilson, S. (2010). The best schools in Auckland and the worst. Metro, 345, July-August, 52-57.

Wilson, S., with McGregor, C. (2011). The best schools in Auckland. Metro, 355, July-August, 44-56.

Wylie, C., Hodgen, E., Hipkins, R., \& Vaughan, K. (2006). Competent learners on the edge of adulthood: A summary of key findings from the Competent Learners @16 Project. Wellington: New Zealand Council for Educational Research. 


\section{The authors}

Martin Thrupp is Professor of Education at the University of Waikato. His research interests are in education policy sociology with a particular focus on how policy plays out in schools in diverse contexts. He is currently undertaking research into the enactment of the National Standards policy in primary schools.

Email: thrupp@waikato.ac.nz

Noeline Alcorn is Emeritus Professor of Education at the University of Waikato. Her research interests include education policy, teacher professional development and educational leadership.

Email:_alcorn@waikato.ac.nz

1 See the Ministry of Education information about the decile system at www.minedu.govt.nz/NZEducation/EducationPolicies/Schools/SchoolOperations/Resourci ng/ResourcingHandbook/Chapter1/DecileRatings.aspx

2 For instance a school may get an unrealistically high decile rating when many children from high SES families in local meshblocks are attending schools further away leaving lower SES students attending the local school.

3 We are grateful to Logan Moss for this analysis.

4 By 2011 other daily newspapers were still presenting the tables alphabetically by school name with the decile in brackets or as one of the columns (i.e., some variant of what is being illustrated by figure 1). Neither the New Zealand Listener nor North and South magazine provide tables of NCEA results but they do provide commentaries on the NCEA and the latter has also provided advice for parents on how to use the NZQA website.

5 All quotes are from teachers or senior management team members at Gandalf College and Tolkien High School. 